\title{
Al-10Mg Nanostructured Alloy by High-energy Mechanical Alloying
}

\author{
J. J. Sánchez-Cuevas ${ }^{1}$, J. Zárate-Medina ${ }^{2}$, O. Navarro ${ }^{3}$ and Gerardo Rosas ${ }^{2}$
}

${ }^{1}$ Universidad Michoacana de San Nicolás de Hidalgo, Jiquilpan, Michoacan de Ocampo, Mexico, ${ }^{2}$ Universidad Michoacana de San Nicolás de Hidalgo, Morelia, Michoacan de Ocampo, Mexico, ${ }^{3}$ Universidad Nacional Autónoma de México, Morelia, Michoacan de Ocampo, Mexico

\section{Introduction}

Mechanical alloying (MA) is a non-equilibrium technique that offers advantages over others, such as low costs and control processing [1]. During MA processing, a high quantity of crystalline defects is induced in the material that can increase the solubility of metals. Additionally, with this route, the obtained nanocrystalline alloy prevents the movement of the dislocations, which improves hardness, fracture tenacity, and wear resistance [2-5].

\section{Experimental procedure}

In this work, the $\mathrm{Al}(\mathrm{Mg}) 10 \mathrm{wt} . \%$ nanostructured alloy was synthesized by high-energy mechanical milling as a function of time. The Al-Mg alloy was formed in a SPEX 8000M ball mill equipment at $1800 \mathrm{rpm}$, with a ball/weight ratio of $7: 1$. Stearic acid (3 wt.\%) was used as the process control agent. The morphological and structural characterization of the as-milled powders was carried out by employing scanning electron microscopy (JEOL JMS-6400), transmission electron microscopy (Phillips TECNAI F20), and X-ray diffraction (Bruker D8 ADVANCE).

\section{Results and discussion}

Fig. 1a shows an SEM micrograph corresponding to the starting material $(0 \mathrm{~h})$, which presents irregular morphology with an average size of $1 \mathrm{~mm}$. An SEM image corresponding to $10 \mathrm{~h}$ milling (Fig. 1b) shows a substantial decrease in particle size associated with the equilibrium between fracture and cold welding near to the end of the solid solution. In the past, it has been widely mentioned that during mechanical alloying, this equilibrium is achieved in different alloy powder systems [6]. Also, it is found that for this milling time, a narrower particle size distribution is obtained with an average size of $16 \mu \mathrm{m}$ and a semi-spherical morphology. However, the alloy structure cannot be refined indefinitely due to the increase in hardness with milling time and crystal size reduction. EDS spectrogram (Fig. 1c) shows the $\mathrm{Al}$ and $\mathrm{Mg}$ elements from the starting material, confirming no signs of contamination. The $\mathrm{O}$ element attributes to the superficial metal oxide formed in both elements. Fig. 1d shows the XRD patterns of the samples corresponding to $0 \mathrm{~h}$, and $10 \mathrm{~h}$ of milling. The XRD belonging to the milling time of $0 \mathrm{~h}$ clearly illustrate the presence of $\mathrm{Al}$ and $\mathrm{Mg}$ reflections (JCPDS no. 00004-0787, JCPDS no. 01-089-4894). As the milling time increases, the diffraction peaks of the aluminum decrease in intensity and become broadened, while the reflections corresponding to the magnesium disappear. This behavior indicates a progressive solid solution formation, as well as a reduction in crystal size accompanied by an increase in the lattice strain. Also, displacements of the Al peaks towards smaller angles are seen, which indicates the increment in the lattice parameter attributed to the $\mathrm{Al}$ substitution by $\mathrm{Mg}$ because the atomic radius of $\mathrm{Mg}(0.160 \mathrm{~nm})$ is higher than $\mathrm{Al}(0.143 \mathrm{~nm})$. After $10 \mathrm{~h}$ of milling time, the $\mathrm{Mg}$ reflections entirely disappear, indicating the formation of the $\mathrm{Al}-10 \mathrm{Mg}$ solid solution. Figs. $2 \mathrm{a}$ and $2 \mathrm{~b}$ show TEM images, which confirm the formation of a nanostructured alloy obtained with an average crystal size between 10-25 $\mathrm{nm}$ after $10 \mathrm{~h}$ MA. From the selected area diffraction pattern, a series of concentric rings corresponding to the (111), (200), (220), (311), and (222) crystallographic planes of the Al-fcc crystal lattice (Fig. 2c) are observed [7]. Fig. 2d displays an HRTEM image, showing a crystal with a size of approximately $20 \mathrm{~nm}$. The interspacing of the HRTEM micrograph corresponds to the interatomic distance of $2.28 \AA$ belonging to the (111) plane of the Al-fcc crystal lattice. Also, the inset shows the FFT pattern confirming the (111) planes of Al. 


\section{Conclusions}

In summary, the Al-10Mg nanostructured alloy was synthesized by high-energy mechanical alloying in a $10 \mathrm{~h}$ milling time. The XRD technique observed that the lattice parameter, strain as well as the solubility of $\mathrm{Mg}$ in $\mathrm{Al}$ increases as the milling time increases. TEM studies display a crystallite size distribution of 10-25 $\mathrm{nm}$. Acknowledgements The author J.J. Sánchez-Cuevas gratefully acknowledges financial support to CONACYT. The UMSNH and Universidad de La Ciénega del Estado de Michoacán de Ocampo for the use of the facilities.
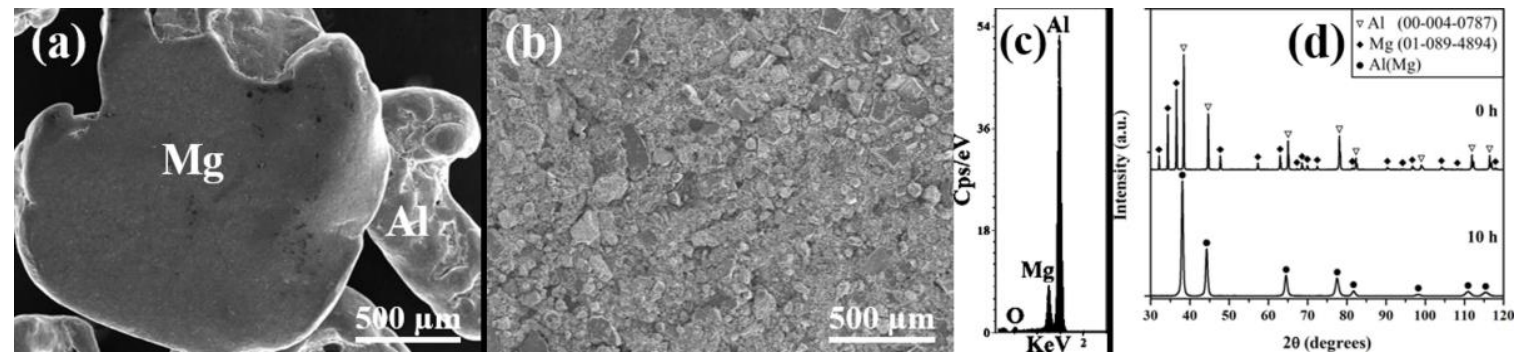

Figure 1. (a)-(b) SEM images corresponding to the milled samples for $0 \mathrm{~h}$, and $10 \mathrm{~h}$, respectively. (c) EDS spectrogram. (d) XRD patterns of the milled samples for $0 \mathrm{~h}$, and $10 \mathrm{~h}$.
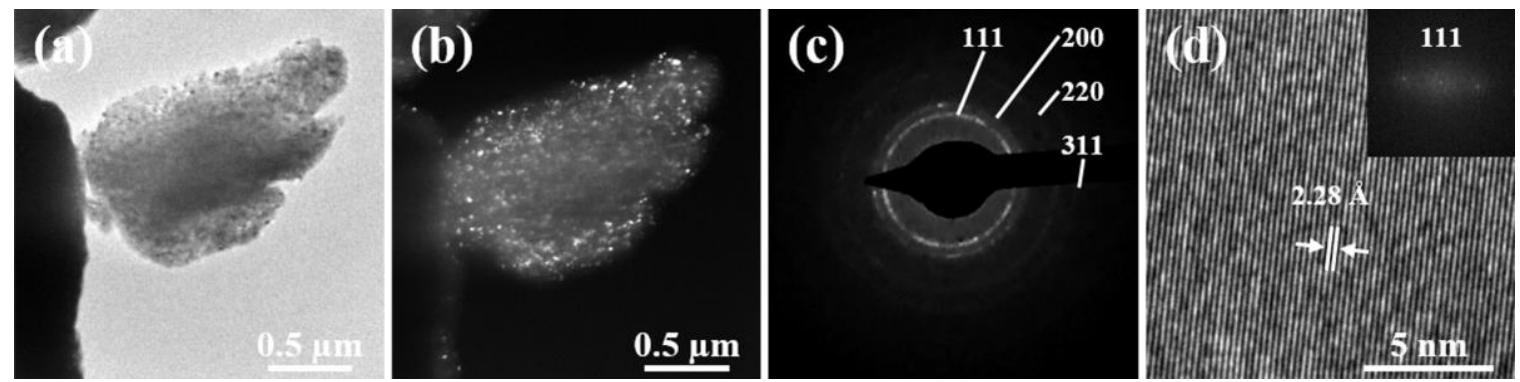

Figure 2. TEM micrographs of Al-10Mg alloy in (a) bright field, (b) dark field, (c) selected area diffraction pattern, and (d) high-resolution with its respective FFT (inset).

\section{References}

[1] S. Maity, A. Sinha, S. Bera. A novel study on mechanically alloyed Al-Mg system by X-ray diffraction technique. Nano-Struct. Nano-Objects. 16 (2018), 63-68.

[2] A. Calka, W. Kaczmarek, J.S. Williams. Extended solid solubility in ball-milled Al-Mg alloys. J. Mater. Sci. 28 (1993), 15-18.

[3] S.M. Umbrajkar, M. Schoenitz, S.R. Jones, E.L. Dreizin. Effect of temperature on synthesis and properties of aluminum-magnesium mechanical alloys. J. Alloys Compd. 402 (2005), 70-77.

[4] R.A. Karnesky, N.Y. Yang, C. San Marchi, T.D. Topping, Z. Zhang, Y. Li, E.J. Lavernia. Solute distribution and mechanical properties of ultra-fine-grained Al-Mg alloys, in: H. Weiland, A.D. Rollett, W.A. Cassada (Eds.), ICAA13, E-Publishing Inc., Pittsburgh, 2012, pp. 1033-1038.

[5] A.K. Chaubey, S. Scudino, M. Samadi Khoshkhoo, K.G. Prashanth, N.K. Mukhopadhyay, B.K. Mishra, J. Eckert. High-strength ultrafine grain Mg-7.4\%Al alloy synthesized by consolidation of mechanically alloyed powders. J. Alloys Compd. 610 (2014), 456-461.

[6] A.K. Chaubey, S. Scudino, M. Samadi Khoshkhoo, K.G. Prashanth, N.K. Mukhopadhyay, B.K. Mishra, J. Eckert. Synthesis and characterization of nanocrystalline Mg-7.4\%Al powders produced by mechanical alloying. Metals. 3 (2013), 58-68.

[7] P.V. Trinh, N.V. Luan, D.D. Phuong, P.N. Minh. Mirostructure and microhardness of aluminum-copper composite reinforced with multi-walled carbon nanotubes prepared by vacuum sintering and hot isostatic pressing techniques. Sci. Sintering. 50 (2018), 163-171. 